\title{
Study of Drug Bottles Using Laser Induced Breakdown Spectroscopy (LIBS)
}

Abeer E. Osman ${ }^{1}$, Ali A. S. Marouf ${ }^{1}$, Mubarak M. Ahmed ${ }^{2}$

${ }^{1}$ Department of Laser Engineering and Industrial Applications, Institute of Laser, Sudan University of Science and Technology, Sudan

2Department of Physics, College of Science and Art, Methane, Qassim University, KSA

\section{ABSTRACT}

There is a great number of packaging materials, such as bottles and boxes, are made of plastics (polymers). Additives such as plasticizers, antioxidants, antistatic agents, and lubricants may be used for the production of packaging materials. The worst effect of plastic production is deterioration of the environment. Recycling solves this problem and the initial step is identification and classification of the polymers and determination of different elements present in it. In this research, spectroscopic analyzes were performed using Laser Induced Breakdown Spectroscopy (LIBS) for plastic materials samples of drug containers that collected from manufacturing factories located at Khartoum city, Sudan. The samples were collected before and after used, were irradiated by Nd: YAG laser at $266 \mathrm{~nm}$, repetition rate $2 \mathrm{~Hz}$, with pulse energy of $80 \mathrm{~mJ}$. The recorded spectra of the samples were analyzed using National Institute Standard and Technology (NIST). and Origin Lab Pro 9 data analysis software. All elements present in plastic drug bottles were detected using laser induced breakdown spectroscopy. The elements that detected are (Ca, Cd, Ra, Ac, W, V, Na, Pm, Cl, K, , Ce, Ar, Nd, Ac, $\mathrm{Tc}, \mathrm{Sc}, \mathrm{Li}, \mathrm{Pa}$, and $\mathrm{Pb}$ ).

Keywords : Laser-induced breakdown spectroscopy (LIBS), Plastic Bottles, Polyethylene terephalate ( PET), Drug store, Waste recycling, Health safety.

\section{INTRODUCTION}

The plastic products and packaging materials are common use in our daily lives [1]. which are generally utilized in various applications such as water and drug bottles, food packaging, medical supplies, and so on $[2,3]$. Because of the many advantages of plastic materials. most important advantages of plastic material are it is soft, transparent, flexible are lightweight, plastics are cost effective, require little energy to produce, and are and biocompatible, or biodegradable and many other of properties [4]. Plastic bottles for oral pharmaceutical products can be manufactured from a wide range of polymer materials including polyethylene terephalate
( PET) being developed to have unique performance properties [5], PET has become from the most favorable packaging material world-wide beverages [6]. The reason for this development is the excellent material properties of the PET material, especially its un-break ability and the very low weight of the bottles compared to glass bottles of the same filling volume, solvent resistant, barrier to gas and moisture $[2,7]$. In spite of that, plastics are helpful in everyday life, except that it must be observed the toxic chemicals compounds utilized in production, in order to environmental and health safety [8].

Laser-induced breakdown spectroscopy (LIBS) has been developed as a new powerful spectroscopic 
technology for chemical detection $[9,10]$. In the LIBS system an intense pulsed laser beam is focused onto the sample surface to produce luminous hot plasma. Optical emissions from the plasma are the result of the de-excitation events of the electronically excited atoms and ions. These spectral emissions are the characteristics of the sample and are identified using the NIST database. The spectral information can be utilized to determine the qualitative and quantitative elemental compositions [11]. LIBS has advantages over other analytical techniques, because there is little or no need for sample preparation; it can be used for rapid real-time analysis in field operations. Remote sensing of samples is also possible since only the photons need to be in direct contact with the sample $[12,13]$. The ability to analyze remotely without contact is especially important when dealing with waste plastics of various sizes and shapes placed on fast-moving conveyor belts. LIBS is a well-known technique for the qualitative and quantitative analysis of trace metals [14].

In this study, the laser induced breakdown spectroscopy was applied to characterize the hazardous and other inorganic trace element constituents in pre-and post-used plastics drug containers.

\section{Materials and Methods}

\section{Preparation of Samples:}

The samples used for testing in this study is plastic materials used in Sudanese drug containers from factories in Khartoum District, Sudan. The samples were collected before and after use, such plastic bottle samples were sterilized and washed with distilled water before it has been tested, to avoid any encountered contamination and to guarantee samples purity. The samples were also cut into slices that are around $3 \mathrm{~cm}^{2}$ in area and $2 \mathrm{~mm}$ in thickness. The total number of drug bottle samples was 9 specimens. All of these details are shown in table (1) that illustrates bottles of drug.

Table (1) drug bottles

\begin{tabular}{|l|l|l|l|}
\hline $\begin{array}{l}\text { bottles } \\
\text { at first }\end{array}$ & $\begin{array}{l}\text { Bottles } \\
\text { Before used }\end{array}$ & $\begin{array}{l}\text { Bottles } \\
\text { After used }\end{array}$ & $\begin{array}{l}\text { drug in } \\
\text { bottle }\end{array}$ \\
\hline $\begin{array}{l}\text { Sample } \\
\text { (S11) }\end{array}$ & Sample (S21) & $\begin{array}{l}\text { Sample } \\
\text { (S31) }\end{array}$ & $\begin{array}{l}\text { AMIBUTA } \\
\text { MOL }\end{array}$ \\
\hline $\begin{array}{l}\text { Sample } \\
\text { (S12) }\end{array}$ & Sample (S22) & $\begin{array}{l}\text { Sample } \\
\text { (S32) }\end{array}$ & $\begin{array}{l}\text { AMIHISTI } \\
\text { N }\end{array}$ \\
\hline $\begin{array}{l}\text { Sample } \\
\text { (S13) }\end{array}$ & Sample (S23) & $\begin{array}{l}\text { Sample } \\
\text { (S33) }\end{array}$ & AMIDOL \\
\hline
\end{tabular}

\section{The experimental setup:}

Samples were analyzed using a RT100-B system (Applied Spectra, Inc) as shown in figure 1. The RT100-B consisted of a 266nm Nd:YAG laser operated at $2 \mathrm{~Hz}$ repetition rate and $80 \mathrm{~mJ}$ pulse energy, we were used Andor Echelle Spectrograph and DT334T ICCD, and an $\mathrm{x}^{-} \mathrm{y}-\mathrm{z}$ translational stage. Gate delay = $0.5 \mathrm{~ns}$, gate width $=2 \mathrm{~ns}$, gain (amplification) $=95$, these parameters are controlled within applied spectra's Axiom software. Gate delay, gate width and gain were optimized for best signal/background(S/B) ratio, while keeping good spectral line resolution and signification signal strength for samples.

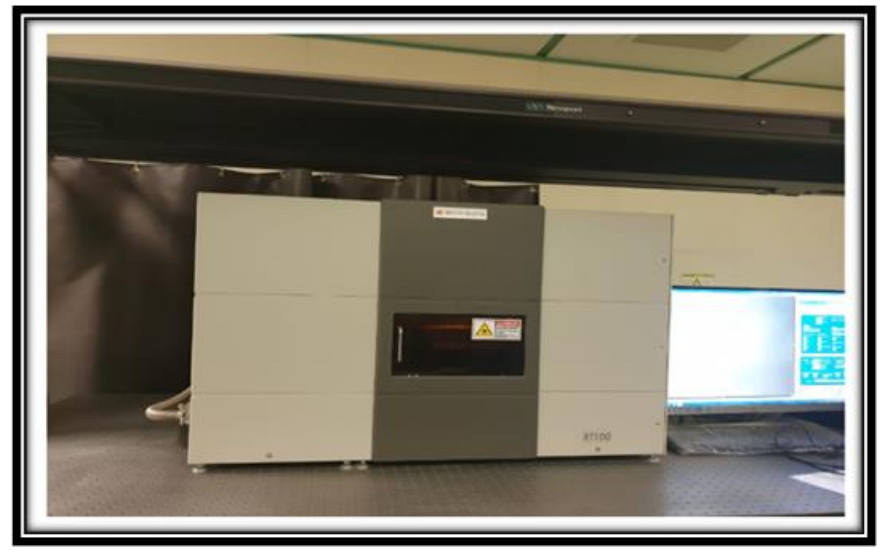

Figure (1). Applied Spectra's RT100 -B/LIBS instrument 


\section{The procedure}

Each sample was mounted in a sample cell and irradiated by the Nd-YAG laser where the sample plasma spark was collected to the spectrometer via a fiber optic, which was interfaces to a computer. The emission spectra were collected within the range from 200-1100 nm within the range. Several LIBS analyses were conducted at its surface in order to check trace elements in drug bottle samples. The recorded spectra of the samples were analyzed using NIST data.

\section{Results and Discussion}

Figures (2) to (10) show the LIBS emission spectra for the samples after irradiation with $80 \mathrm{~mJ}$ pulse energy. Tables (2) to (10) list the analysis of the wavelengths corresponding to different elements and their intensities in the nine samples.

\section{LIBS results of the drug bottles samples at first (group} 1):

All of the plastic drug bottles samples divided into three groups. The first group (S11,S12 and S13) that drug bottles at first, the second group (S21,S22 and S23) , and the last one consists of (S31,S32and S33) were sampled using the LIBS technique to assess the presence and amounts of certain elements (in this case , Ca, Cd , Ra, Ac, W, V, Na, Pm, Cl, K, , Ce, Ar, $\mathrm{Nd}, \mathrm{Ac}, \mathrm{Tc}, \mathrm{Sc}, \mathrm{Li}, \mathrm{Pa}$, and $\mathrm{Pb}$ ). Difference in the spectral lines between the different samples, which would be expected, because there are different between the groups (S11, S12 and S13) were before preparation (S21, S22and S23) were the bottles before used and at last (S31, S32 and S33) were the bottles after used. That caused the charred surfaces simply were to add or remove some elements. Figures (2), (3) and (4) show the spectral lines of (S11, S12 andS13) samples. The spectra for all these samples represented in the range (200 - 1150) wavelengths by nanometers.
Figure (2) for sample S11 shows 6 peaks, as tabling in table (2) and they were analyzed to their corresponding elements (Os I, Pt I, Pb I, Nb II, Tc I and W I). Figure 3 for sample S12 shows 17 peaks, as tabling in table (3) and they were analyzed to their corresponding elements (Os I, Pt I, W I, Fe I, Gd II, Nb I, V I, Ca I, Na I, Er II, Eu II, K I, Ne I and Xe I). Whereas, many elements have two peaks because of the different chemical compounds and states of existence these elements can attain (W I, Ca II and Na II) as shown in figure (3). At last samples in first group S13 at figure (4) shows 12 peaks, as tabling in table (4) and analyzed to their corresponding elements (Pt I, Pu I, Cr I, Ce II, Tb II, Ca I, Pr II, Li II, Na I, Eu I, Cd II and F I).

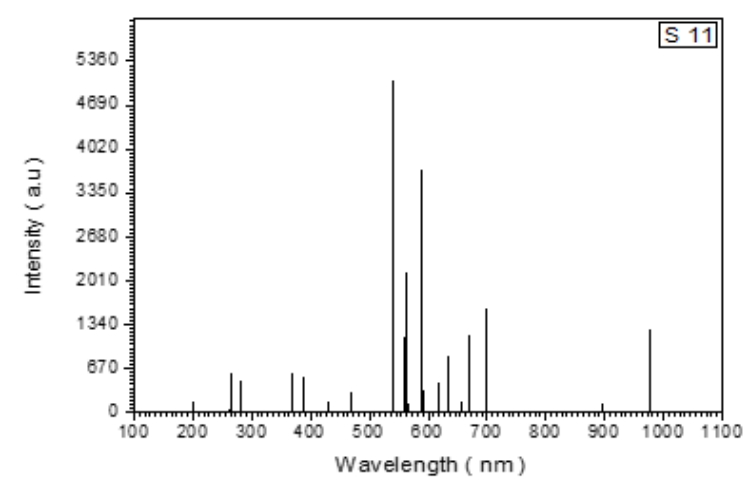

Figure 2. LIBS emission spectrum of sample (S11).

Table (2) The analyzed data of sample S11, irradiated by $80 \mathrm{~mJ}$

\begin{tabular}{|c|c|c|}
\hline $\begin{array}{c}\text { Measured } \lambda \\
(\mathrm{nm})\end{array}$ & Intensity (a.u ) & Elements \\
\hline 200.145 & 1169 & Os I \\
\hline 265.415 & 1609 & $\mathrm{Pt} \mathrm{I}$ \\
\hline 280.108 & 1507 & $\mathrm{~Pb} \mathrm{I}$ \\
\hline 367.357 & 1645 & $\mathrm{Nb}$ II \\
\hline 386.824 & 1574 & $\mathrm{Tc} \mathrm{I}$ \\
\hline 429.461 & 1306 & $\mathrm{~W} \mathrm{I}$ \\
\hline
\end{tabular}




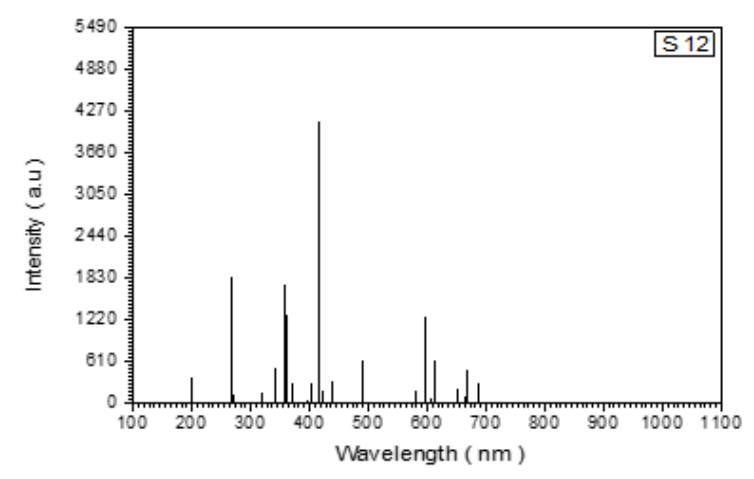

Figure 3. LIBS emission spectrum of sample (S12).

Table (3) The analyzed data of sample S12, irradiated by $80 \mathrm{~mJ}$

\begin{tabular}{|c|c|c|}
\hline $\begin{array}{c}\text { Measured } \lambda \\
(\mathrm{nm})\end{array}$ & Intensity (a.u ) & Elements \\
\hline 200.145 & 381 & Os I \\
\hline 265.945 & 1836 & Pt I \\
\hline 269.567 & 160 & W I \\
\hline 319.329 & 182 & Fe I \\
\hline 342.490 & 554 & Gd II \\
\hline 358.946 & 1783 & Nb I \\
\hline 404.551 & 316 & V I \\
\hline 417.117 & 4142 & W I \\
\hline 422.673 & 201 & Ca I \\
\hline 440.512 & 351 & Na I \\
\hline 490.003 & 600 & Er II \\
\hline 585.745 & 209 & Ca I \\
\hline 596.607 & 1313 & Eu II \\
\hline 612.027 & 580 & K I \\
\hline 651.421 & 235 & Na II \\
\hline 667.583 & 460 & Ne I \\
\hline 687.211 & 316 & Xe I \\
\hline
\end{tabular}

\begin{tabular}{|c|c|c|}
\hline $\begin{array}{c}\text { Measured } \lambda \\
(\mathrm{nm})\end{array}$ & Intensity (a.u ) & Elements \\
\hline 265.954 & 730 & Pt I \\
\hline 324.520 & 478 & Pu I \\
\hline 390.291 & 2541 & Cr I \\
\hline 456.236 & 225 & Ce II \\
\hline 470.241 & 1216 & Tb II \\
\hline 518.885 & 596 & Ca I \\
\hline 522.011 & 201 & Pr II \\
\hline 548.511 & 1548 & Li II \\
\hline 589.593 & 243 & Na I \\
\hline 601.815 & 1034 & Eu I \\
\hline 635.472 & 116 & Cd II \\
\hline 685.603 & 277 & F I \\
\hline
\end{tabular}

LIBS results of the drug bottles samples before use (group 2):

The second group was (S21, S22 and S23) are showing the chemical compounds spectra for all of these samples in figures (5), (6) and (7). The spectra for all this samples represented in the range (200 - 1150) wavelengths by nanometers. Figure (5) for sample S21 shows 12 peaks, as tabling in table (5) and analyzed to their corresponding elements (Pt I, Ni I, Ar I, Ra II, $\mathrm{Na}$ II, K I, Er II, Ca I and Kr I) but (K I and Na II) 
elements have two peaks or more as shown in figure (5). Whereas. Figure (6) sample S22 shows 15 peaks, as tabling in table (6) and analyzed to their corresponding elements (W I, Er II, Bk I, Ra II, Tc I, Pa I, K II, Ca I, He II, Pm I, Xe II, Al I and Eu II) but (Ca I and K I) elements have two peaks as shown in figure (6). The last sample in the second group S23 at figure (7) shows 8 peaks, as tabling in table (7) and analyzed to their corresponding elements (Er II, Tc I, Pa I, K II, He II and Pr I) but (K I) element have three peaks.

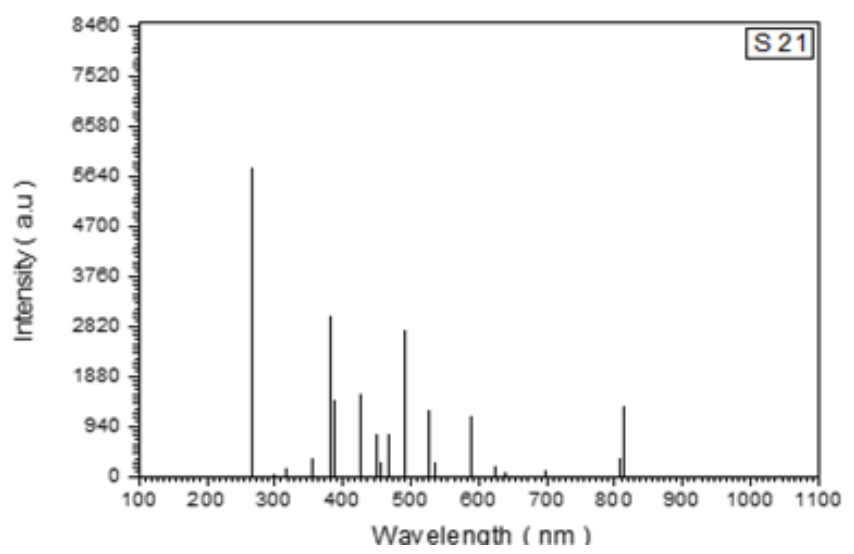

Figure 5. LIBS emission spectrum of sample (S21).

Table (5) The analyzed data of sample S21, irradiated by $80 \mathrm{~mJ}$

\begin{tabular}{|c|c|c|}
\hline $\begin{array}{c}\text { Measured } \lambda \\
(\mathrm{nm})\end{array}$ & Intensity (a.u ) & Elements \\
\hline 265.945 & 5866 & $\mathrm{Pt} \mathrm{I}$ \\
\hline 354.818 & 383 & Ni I \\
\hline 386.492 & 3062 & Ra II \\
\hline 425.936 & 1512 & Ar I \\
\hline 449.087 & 856 & Na II \\
\hline 464.237 & 774 & K II \\
\hline 490.007 & 2756 & Er II \\
\hline 526.556 & 1304 & Ca I \\
\hline 534.294 & 331 & K I \\
\hline 589.592 & 1162 & Na I \\
\hline 807.962 & 363 & K I \\
\hline 813.296 & 1304 & Kr I \\
\hline
\end{tabular}

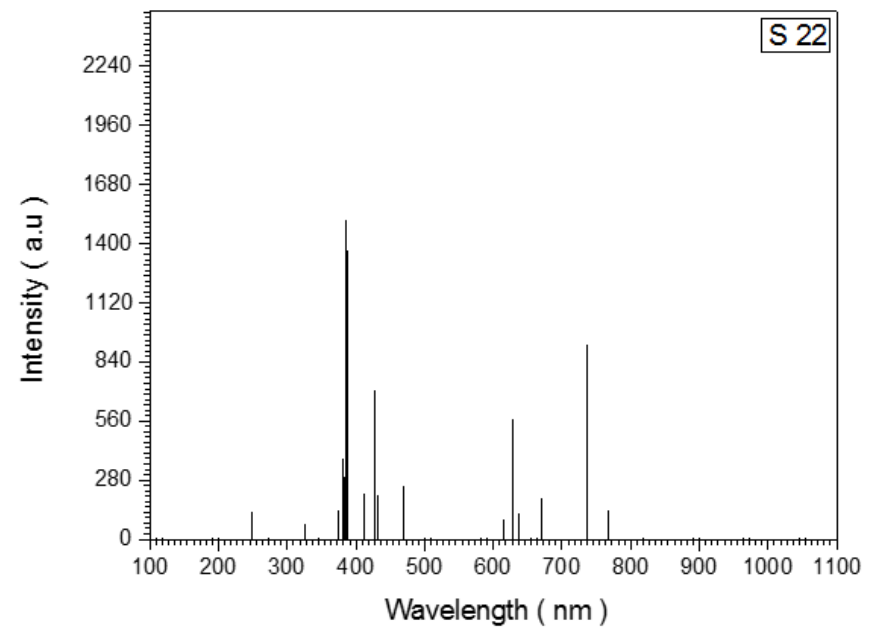

Figure 6. LIBS emission spectrum of sample (S22).

Table (6) The analyzed data of sample S22, irradiated by $80 \mathrm{~mJ}$

\begin{tabular}{|c|c|c|}
\hline $\begin{array}{c}\text { Measured } \lambda \\
(\mathrm{nm})\end{array}$ & $\begin{array}{c}\text { Intensity } \\
(\mathrm{a} . \mathrm{u})\end{array}$ & Elements \\
\hline 248.144 & 143 & $\mathrm{~W} \mathrm{I}$ \\
\hline 326.478 & 71 & Er II \\
\hline 372.538 & 131 & Bk I \\
\hline 381.442 & 336 & Ra II \\
\hline 386.824 & 1472 & Tc I \\
\hline 411.762 & 215 & Pa I \\
\hline 426.340 & 697 & K II \\
\hline 430.774 & 209 & Ca I \\
\hline 468.580 & 263 & He II \\
\hline 616.217 & 95 & Ca I \\
\hline 628.606 & 564 & Pm I \\
\hline 637.528 & 113 & Xe II \\
\hline 669.602 & 198 & Al I \\
\hline 737.022 & 937 & Eu II \\
\hline 769.897 & 145 & K I \\
\hline
\end{tabular}




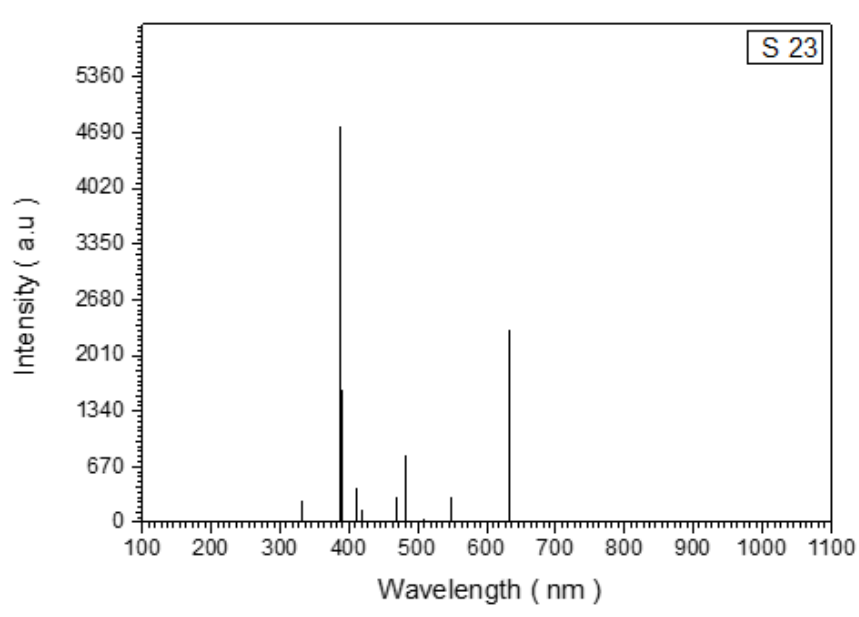

Figure 7. LIBS emission spectrum of sample (S23).

Table (7) The analyzed data of sample S23, irradiated by $80 \mathrm{~mJ}$

\begin{tabular}{|c|c|c|}
\hline $\begin{array}{c}\text { Measured } \lambda \\
(\mathrm{nm})\end{array}$ & Intensity (a.u ) & Elements \\
\hline 331.639 & 242 & Er II \\
\hline 386.824 & 4774 & Tc I \\
\hline 411.762 & 458 & Pa I \\
\hline 418.624 & 198 & K II \\
\hline 468.581 & 328 & He II \\
\hline 482.923 & 834 & K I \\
\hline 598.614 & 344 & Pr I \\
\hline 630.729 & 2307 & K I \\
\hline
\end{tabular}

LIBS results of the drug bottles samples after use (group 3):

The chemical compound spectra of the last group (S31, S32 and S33) are shown in figures (8), (9) and (10). The spectra for all of these samples represents in the range (200 - 1150) wavelengths by nanometers. Figure (8) for sample S31 shows 13 peaks, as tabling in table (8) and analyzed to their corresponding elements (Cd II, Ra II, Ac I, V I, Pm I, Ca I, Cl I, and $\mathrm{K}$ I) but both (Na II and W I) shows two peaks. Whereas, figure (9) for sample S32 shows 11 peaks, as tabling in table (9) and analyzed to their corresponding elements (Ar II, Nd II, Ac I, Pm I, Ca I,
Tc I, Cl II, Na II, Sc I, Pb I and Pa I). The last sample in the third group S33 at Figure (10) shows 9 peaks, as tabling in table (10) and analyzed to their corresponding elements (Tc I, Nd II, V I, K I, Li II, Pm II, Ce I and Cl I) but only (K I) shows two peaks.

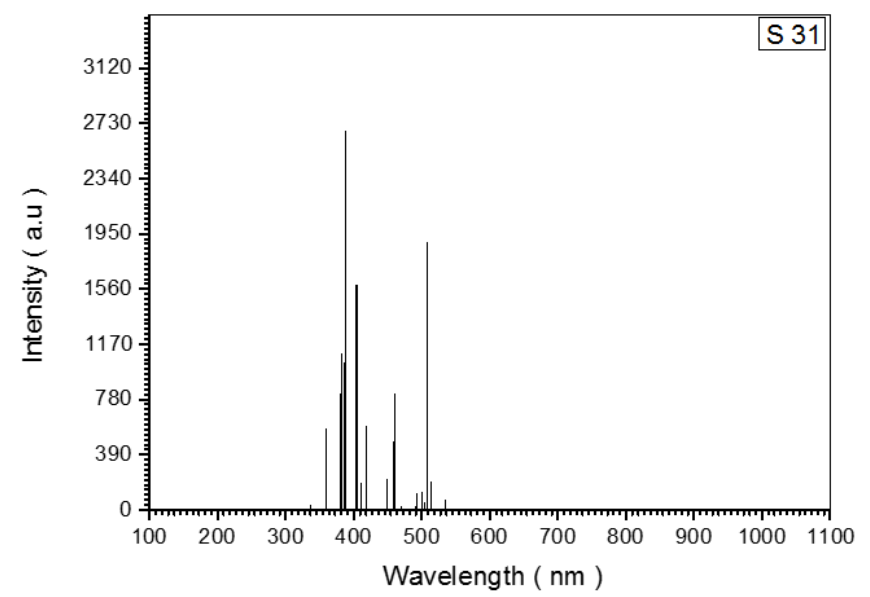

Figure 8. LIBS emission spectrum of sample (S31).

Table (8) The analyzed data of sample S31, irradiated by $80 \mathrm{~mJ}$.

\begin{tabular}{|c|c|c|}
\hline $\begin{array}{c}\text { Measured } \lambda \\
(\mathrm{nm})\end{array}$ & Intensity (a.u ) & Elements \\
\hline 358.496 & 604 & Cd II \\
\hline 381.442 & 1143 & Ra II \\
\hline 388.556 & 2677 & Ac I \\
\hline 404.559 & 1598 & W I \\
\hline 409.978 & 167 & V I \\
\hline 417.117 & 588 & W I \\
\hline 449.087 & 217 & Na II \\
\hline 459.755 & 815 & Pm I \\
\hline 487.817 & 133 & Ca I \\
\hline 499.547 & 125 & Cl I \\
\hline 514.883 & 225 & Na I \\
\hline 533.969 & 65 & K I \\
\hline
\end{tabular}




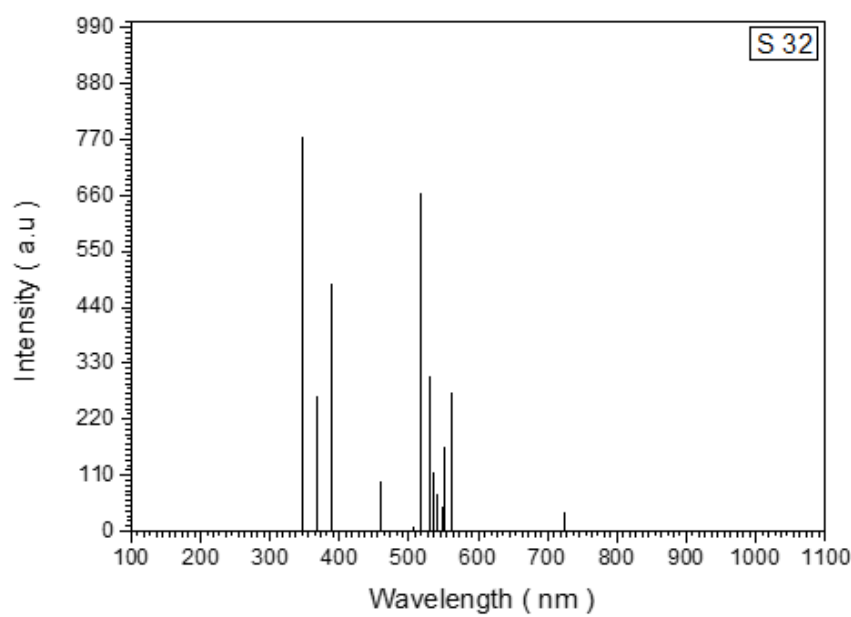

Figure 9. LIBS emission spectrum of sample (S32).

Table (9) The analyzed data of sample S32, irradiated by $80 \mathrm{~mJ}$

\begin{tabular}{|c|c|c|}
\hline $\begin{array}{c}\text { Measured } \lambda \\
(\mathrm{nm})\end{array}$ & Intensity (a.u ) & Elements \\
\hline 347.675 & 779 & Ar II \\
\hline 367.354 & 269 & $\mathrm{Nd} \mathrm{II}$ \\
\hline 388.556 & 486 & $\mathrm{Ac} \mathrm{I}$ \\
\hline 459.755 & 98 & $\mathrm{Pm} \mathrm{I}$ \\
\hline 518.885 & 666 & $\mathrm{Ca} \mathrm{I}$ \\
\hline 528.507 & 308 & $\mathrm{Tc} \mathrm{I}$ \\
\hline 539.212 & 117 & $\mathrm{Cl} \mathrm{II}$ \\
\hline 541.455 & 72 & $\mathrm{Na} \mathrm{II}$ \\
\hline 552.052 & 156 & $\mathrm{Sc} \mathrm{I}$ \\
\hline 560.885 & 274 & $\mathrm{~Pb} \mathrm{I}$ \\
\hline 722.713 & 45 & $\mathrm{~Pa} \mathrm{I}$ \\
\hline
\end{tabular}

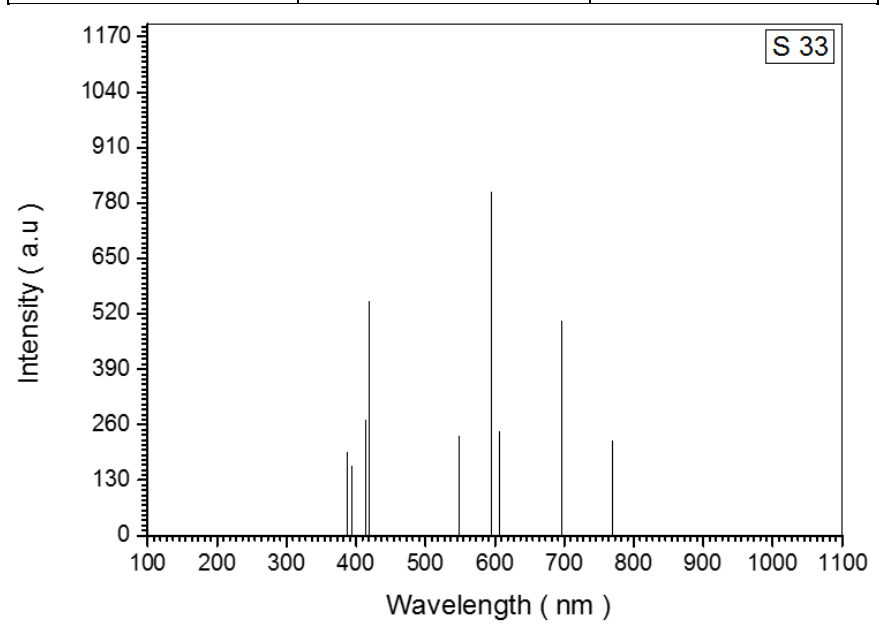

Figure 10. LIBS emission spectrum of sample (S33).
Table (10) The analyzed data of sample S33, irradiated by $80 \mathrm{~mJ}$

\begin{tabular}{|c|c|c|}
\hline $\begin{array}{c}\text { Measured } \lambda \\
(\mathrm{nm})\end{array}$ & Intensity (a.u ) & Elements \\
\hline 386.824 & 198 & Tc I \\
\hline 393.888 & 172 & Nd II \\
\hline 413.448 & 271 & V I \\
\hline 418.624 & 554 & K II \\
\hline 548.511 & 230 & Li II \\
\hline 594.649 & 808 & Pm II \\
\hline 607.201 & 245 & Ce I \\
\hline 696.418 & 502 & K I \\
\hline 767.242 & 224 & Cl I \\
\hline
\end{tabular}

For all samples the detection limit is $(200-1150 \mathrm{~nm})$ depending on the sensitivity of the detector, it was out of the range of the main elements that the drug containers polyethylene terephthalate (PET) made of. $(\mathrm{C}$ and $\mathrm{H}$ ) elements in the range before $200 \mathrm{~nm}$ for this rezone these two elements were not appear in the results.

The LIBS spectra showed that the elements of (S11, S21and S31) samples that drug bottles (AMIBUTAMOL DRUG) are (Os I, Pt I, Pb I, Nb II, Tc I and W I) for sample S 11 (bottle at first Bottle), ( Pt I, Ni I, Ar I, Ra II, Na II, K II, Er II, Ca I and Kr I) for sample S21 (Before used Bottle) and (Cd II, Ra II, Ac I, V I, Pm I, Ca I, Cl I, and K I, NaI, W I ) for sample S31 (After used). Some elements in sample S31 were not found in in sample S11 and sample S21 like (Cd II, Ac I, V I, C 1 I, and Pm I). This group is bad recycling samples.

For LIBS spectra (finger print wavelength) for (AMIHISTIN DRUG) are ( Os I, Pt I, W I, Fe I, Gd II, $\mathrm{Nb}$ I, V I, Ca I, Na I, Er II, Eu II, K I, Ne I and Xe I) for S 12 sample (bottle at first), (W I, Er II, Bk I, Ra II, Tc I, Pa I, K II, Ca I, He II, Pm I, Xe II, Al I and Eu II) for $\mathrm{S} 22$ sample (Before used Bottle) and element (Ar II, Nd II, Ac I, Pm I, Ca I, Tc I, Cl II, Na II, Sc I, Pb I 
and $\mathrm{Pa}$ I) for S32 sample (After used). There are some strange elements like ( $\mathrm{Ar}, \mathrm{Nd}, \mathrm{Ac}, \mathrm{Cl}, \mathrm{Sc}$, and $\mathrm{Pb}$ ) some of these elements are agree with the results of previous studies $[15,16)$, also all elements for above samples of this group is bad recycling samples.

At the last group (AMIDOL DRUG) the finger print elements of LIBS spectra are (Pt I, Pu I, Cr I, Ce II, Tb II, Ca I, Pr II, Li II, Na I, Eu I, Cd II and F I) for sample S 13 (bottle at first Bottle), (Er II, Tc I, Pa I, K II, He II and Pr I) for sample S 23 (Before used Bottle) and (Tc I, Nd II, V I, K I, Li II, Pm II, Ce I and Cl I) for $\mathrm{S} 33$ sample (After used). There are some strange elements like (Tc I, Ce I, Nd I, V I , Li II, Pm , and K I). For above elements this group is bad recycling samples also.

\section{CONCLUSIONS}

All elements present in plastic drug bottles were detected using laser induced breakdown spectroscopy. The elements that detected are (Ca, Cd , Ra, Ac, W, V, Na, Pm, Cl, K, , Ce, Ar, $\mathrm{Nd}, \mathrm{Ac}, \mathrm{Tc}, \mathrm{Sc}, \mathrm{Li}, \mathrm{Pa}$, and $\mathrm{Pb}$ ).

Element that present in plastic drug bottles samples were estimated and results achieved are in good agreement and all of these elements were normal and this group is not useful for recycling.

The sensitive lines for the above-mentioned heavy elements were identified using standard data published by NIST for the elemental analysis in different plastic and drug bottles samples.

This study reveals that the plastic drug bottles samples collected from manufacturing factories located at Khartoum city, Sudan. They could cause a lot of problems in recycling, it is not recommended recycling this samples.

\section{REFERENCES}

[1]. Saquing, J. M., Saquing, C. D., Knappe, D. R., \& Barlaz, M. A. (2010). Impact of plastics on fate and transport of organic contaminants in landfills. Environmental science \& technology, 44(16), 6396-6402.

[2]. Alabi, O. A., Ologbonjaye, K. I., Awosolu, O., \& Alalade, O. E. (2019). Public and Environmental Health Effects of Plastic Wastes Disposal: A Review. J Toxicol Risk Assess, 5, 021.

[3]. Liu, K., Tian, D., Yue, X., \& Yang, G. (2020). A software system for rapid analysis of plastics using laser-induced breakdown spectroscopy. Journal of Instrumentation, 15(04), T04002.

[4]. Proshad, R., Kormoker, T., Islam, M. S., Haque, M. A., Rahman, M. M., \& Mithu, M. M. R. (2018). Toxic effects of plastic on human health and environment: A consequences of health risk assessment in Bangladesh. International Journal of Health, 6(1), 1-5.

[5]. Campbell, G. A., \& Vallejo, E. (2015). Primary packaging considerations in developing medicines for children: oral liquid and powder for constitution. Journal of pharmaceutical sciences, 104(1), 52-62

[6]. Welle, F. (2011). Twenty years of PET bottle to bottle recycling-an overview. Resources, Conservation and Recycling, 55(11), 865-875.

[7]. Grégoire, S., Boudinet, M., Pelascini, F., Surma, F., Detalle, V., \& Holl, Y. (2011). Laserinduced breakdown spectroscopy for polymer identification. Analytical and bioanalytical chemistry, 400(10), 3331-3340.

[8]. Bach, C., Dauchy, X., Chagnon, M. C., \& Etienne, S. (2012). Chemical compounds and toxicological assessments of drinking water stored in polyethylene terephthalate (PET) bottles: a source of controversy reviewed. Water research, 46(3), 571-583. 
[9]. Liu, K., Tian, D., Li, C., Li, Y., Yang, G., \& Ding, Y. (2019). A review of laser-induced breakdown spectroscopy for plastic analysis. TrAC Trends in Analytical Chemistry, 110, 327-334.

[10]. Waheed, S., Rahman, S., Husnain, S., \& Siddique, N. (2012). Hazardous and other element characterization of new and used domestic plastic food containers using INAA and AAS. Journal of Radioanalytical and Nuclear Chemistry, 292(3), 937-945.

[11]. Junjuri, R., \& Gundawar, M. K. (2019). Femtosecond laser-induced breakdown spectroscopy studies for the identification of plastics. Journal of Analytical Atomic Spectrometry, 34(8), 1683-1692.

[12]. Anabitarte, F., Cobo, A., \& Lopez-Higuera, J. M. (2012). Laser-induced breakdown spectroscopy: fundamentals, applications, and challenges. ISRN Spectroscopy, 2012.

[13]. Anzano, J. M., Bello-Gálvez, C., \& Lasheras, R. J. (2014). Identification of Polymers by Means of LIBS. In Laser-Induced Breakdown Spectroscopy (pp. 421-438). Springer, Berlin, Heidelberg.

[14]. Kim, E., \& Choi, W. Z. (2019). Real-time identification of plastics by types using laserinduced breakdown spectroscopy. Journal of Material Cycles and Waste Management, 21(1), 176-180.

[15]. Cheng, X., Shi, H., Adams, C. D., \& Ma, Y. (2010). Assessment of metal contaminations leaching out from recycling plastic bottles upon treatments. Environmental Science and Pollution Research, 17(7), 1323-1330

[16]. Koyuncu, M., \& Alwazeer, D. (2019). Determination of trace elements, heavy metals, and antimony in polyethylene terephthalatebottled local raw cow milk of Iğdır region in Turkey. Environmental monitoring and assessment, 191(11), 666.

\section{Cite this article as :}

Abeer E. Osman, Ali A . S. Marouf, Mubarak M. Ahmed, "Study of Drug Bottles Using Laser Induced Breakdown Spectroscopy (LIBS)", International Journal of Scientific Research in Science and Technology (IJSRST), Online ISSN : 2395-602X, Print ISSN : 2395-6011, Volume 7 Issue 3, pp. 442-450, May-June 2020. Available at doi $\quad$ : https://doi.org/10.32628/IJSRST207388 Journal URL : http://ijsrst.com/IJSRST207388 